\title{
Correction: MII RetCam assisted smartphone-based fundus imaging (MSFI)—a boon for paediatric retinal imaging
}

Rajwinder Kaur · Harijot Singh • Shallu Samria • Nilesh Kumar D - Nikulaa Parachuri • Rohini Sharma • Francesco Bandello · Anat Loewenstein · Yannick Bilong • M. Hafeez Faridi • Ashish Sharma

Published online: 6 August 2020

(c) The Royal College of Ophthalmologists 2020

Correction to: Eye

https://doi.org/10.1038/s41433-020-0822-3
Since publication, it was noticed that author Dr Francesco Bandello's name was displayed incorrectly. The authors apologise for this error. 